\title{
Minimally invasive surgery for thoracolumbar spinal trauma
}

\author{
Corey T. Walker ${ }^{1}$, David S. Xu ${ }^{1}$, Jakub Godzik ${ }^{1}$, Jay D. Turner ${ }^{1}$, Juan S. Uribe ${ }^{1}$, William D. Smith ${ }^{2}$ \\ ${ }^{1}$ Department of Neurosurgery, Barrow Neurological Institute, St. Joseph's Hospital and Medical Center, Phoenix, Arizona, USA; ${ }^{2}$ Department of \\ Neurosurgery, University Medical Center of Southern Nevada, Las Vegas, Nevada, USA \\ Contributions: (I) Conception and design: WD Smith, JS Uribe, CT Walker; (II) Administrative support: WD Smith, JS Uribe; (III) Provision of \\ study materials or patients: JD Turner, WD Smith, JS Uribe; (IV) Collection and assembly of data: J Godzik, CT Walker, DS Xu; (V) Data analysis \\ and interpretation: J Godzik, CT Walker, DS Xu; (VI) Manuscript writing: All authors; (VII) Final approval of manuscript: All authors. \\ Correspondence to: Corey T. Walker, MD. Department of Neurosurgery, Barrow Neurological Institute, St. Joseph's Hospital and Medical Center, \\ 350 W. Thomas Rd., Phoenix, AZ 85013, USA. Email: Neuropub@dignityhealth.org.
}

\begin{abstract}
The indications for operative intervention after thoracolumbar spine trauma have been well described. Advances in minimally invasive techniques, including percutaneous pedicle screw fixation and mini-open anterolateral retractor-based approaches can improve surgical outcomes when appropriately applied by reducing blood loss, operative duration and post-operative pain. Moreover, they allow for theoretical advantages by preservation of muscular and skeletal blood supply and innervation that is typically lost during the muscular dissection of open approaches. For thoracolumbar spine fractures, percutaneous fixation allows for internal bracing of unstable fractures during healing while maintaining sagittal alignment. In instances of neurological compromise from fracture retropulsion, corpectomies may be required, and mini-open lateral approaches adopted from degenerative disease applications allow for a minimally invasive manner to treat the defect. These further allow for placement of wide rectangular-footprint expandable vertebral body replacement devices to provide anterior column support. We believe this allows for lower rates of subsidence and helps to maintain the biomechanical integrity necessary to prevent post-traumatic malalignment and kyphosis. Together, these minimally invasive techniques combined supply the spine surgeon with a minimally invasive armamentarium to treat nearly all thoracolumbar spine trauma. Surgeons should be comfortable with the strengths and shortcomings of these approaches in order to successfully apply them for this pathology.
\end{abstract}

Keywords: Lateral interbody fusion; corpectomy; arthrodesis; minimally invasive; extreme lateral interbody fusion (XLIF); percutaneous; pedicle screw fixation; trauma; burst fracture; thoracolumbar

Submitted Dec 03, 2017. Accepted for publication Jan 31, 2018.

doi: $10.21037 / \mathrm{atm} .2018 .02 .10$

View this article at: http://dx.doi.org/10.21037/atm.2018.02.10

\section{Introduction}

Treatment of trauma to the thoracic and lumbar spine has been the focus of surgeons for decades due to the associated decision-making complexity and various directions of approach. Increasing understanding of the biomechanics, pathophysiology and natural history for the various spinal column injury types has allowed for better prognostication and has helped to dictate indications for surgical intervention. The thoracolumbar injury classification and severity score (TLICS) score can assist in this decision making, and is based on the morphology of the injury, the integrity of the posterior ligamentous complex, and the presence of neurological injury $(1,2)$. Additionally, those patients at risk of developing significant deformity, who have incapacitating pain, or are unable to tolerate external bracing may benefit from surgical intervention.

When intervention is warranted, posterior, anterior or combined anterior-posterior approaches can be considered, each with its own distinct advantages. Historically, posterior spinal approaches have involved large segment, open fixation techniques with dorsal decompression and 
correction of sagittal alignment if needed. Likewise, anterior approaches utilizing a thoracotomy could be performed to directly decompress the neural elements and restore biomechanical support through anterior column reconstruction with vertebral body replacement implants. More recently, minimally invasive techniques have gained traction due to advantages with regard to minimizing paraspinal tissue damage during the approach. As such, utilization of these approaches for some instances in spinal trauma may achieve similar benefits while decreasing patient morbidity and potentially improving outcomes.

In this review, we highlight the main types of spinal trauma, and how minimally invasive techniques may be appropriately applied. Specifically, we describe lateral approaches that may be used to access the anterior column for corpectomies. Additionally, we will discuss percutaneous posterior fixation applications for unstable fractures. Some of the literature supporting the use of these methodologies is examined. Limitations will be noted and identified accordingly.

\section{Percutaneous posterior spinal fixation}

Unstable fractures may require internal fixation with pedicle screw instrumentation to limit segmental motion while they heal. Additionally, for some patients, external bracing may not be an option, and surgical treatment must be considered. A number of studies have suggested that percutaneous placement may have significant advantages over traditional open posterior approaches as it does not require the extensive retraction, devascularization and denervation of the paraspinal musculature. Additionally, the procedure comes with shorter operative duration, decreased blood loss and reduced pain, which in turn may help lead to faster recovery times and shorter hospital stays (3-5).

While there has been some contention regarding the need for posterior arthrodesis, several studies comparing fixation without fusion to traditional techniques have demonstrated similar outcomes at long-term follow-up (6-11). It is thought that posterior arthrodesis allows for preserved kyphosis that cannot be achieved with fixation alone, however, it seems likely that many patients with fixation alone likely fuse though this has not been directly assessed. For cases of percutaneous pedicle screw fixation alone, removal of hardware may be offered after fracture healing is complete in hopes that mobility may be maintained across this segment if fusion has not occurred. In a study examining fixation without fusion, instrumentation removal at 9-12 months post-op caused a small but statistically significant decrease in the amount of original kyphosis correction, though this did not result in a worsening of clinical outcomes (12). Other studies directly comparing percutaneous pedicle screw fixation and posterior open fusion have also suggested that no difference in results could be seen between the two methodologies at long-term follow-up $(5,13,14)$. While conclusive data remains to be seen, it is likely that this data collectively suggests that short segment percutaneous fixation provides sufficient biomechanical support to maintain spinal alignment when applied to appropriate patients and clinical circumstances. Surgeons may counsel patients upfront at the time of surgery of a relatively low risk of long-term post-operative kyphosis, and the potential for a larger open operation if this develops.

\section{Thoracolumbar burst fractures}

The vast majority of studies above have applied percutaneous fixation to the treatment of unstable thoracolumbar burst fractures (15) These are best applied to cases where there is no neurological symptoms related to bone fragment retropulsion in the spinal canal. In these instances, the instrumentation acts as an internal bracing while fracture healing occurs. It is unclear whether posterior ligamentous injury affects the long-term viability of this approach, however, some authors argue that extensive disruption may be suggestive of better treatment with posterior fusion (16).

In the authors' experience (JS Uribe, JD Turner and WD Smith), short-segment fixation (one level above and below the fracture) with a short screw (25-35 $\mathrm{mm}$ in length) through the pedicle at the index level provides substantial biomechanical support to allow for appropriate healing. Compromise of the pedicle(s) may prohibit placement of an index level screw. Likewise, compromised bone integrity at an adjacent level may warrant extension to an additional level to ensure appropriate purchase (9). While the authors typically employ biplanar fluoroscopy for screw placement, navigated screw placement can also be considered based on surgeon preference and comfort with each technique. Attention to K-wire localization is imperative at all times, particularly at the fractured level, in order to prevent unintentional advancement through the body into critical vascular structures (17).

For many burst fractures, prone placement of the patient on the operating room bed causes postural reduction of the traumatic deformity. In cases of severe angulation or kyphosis, it may be best to consider an open approach such 

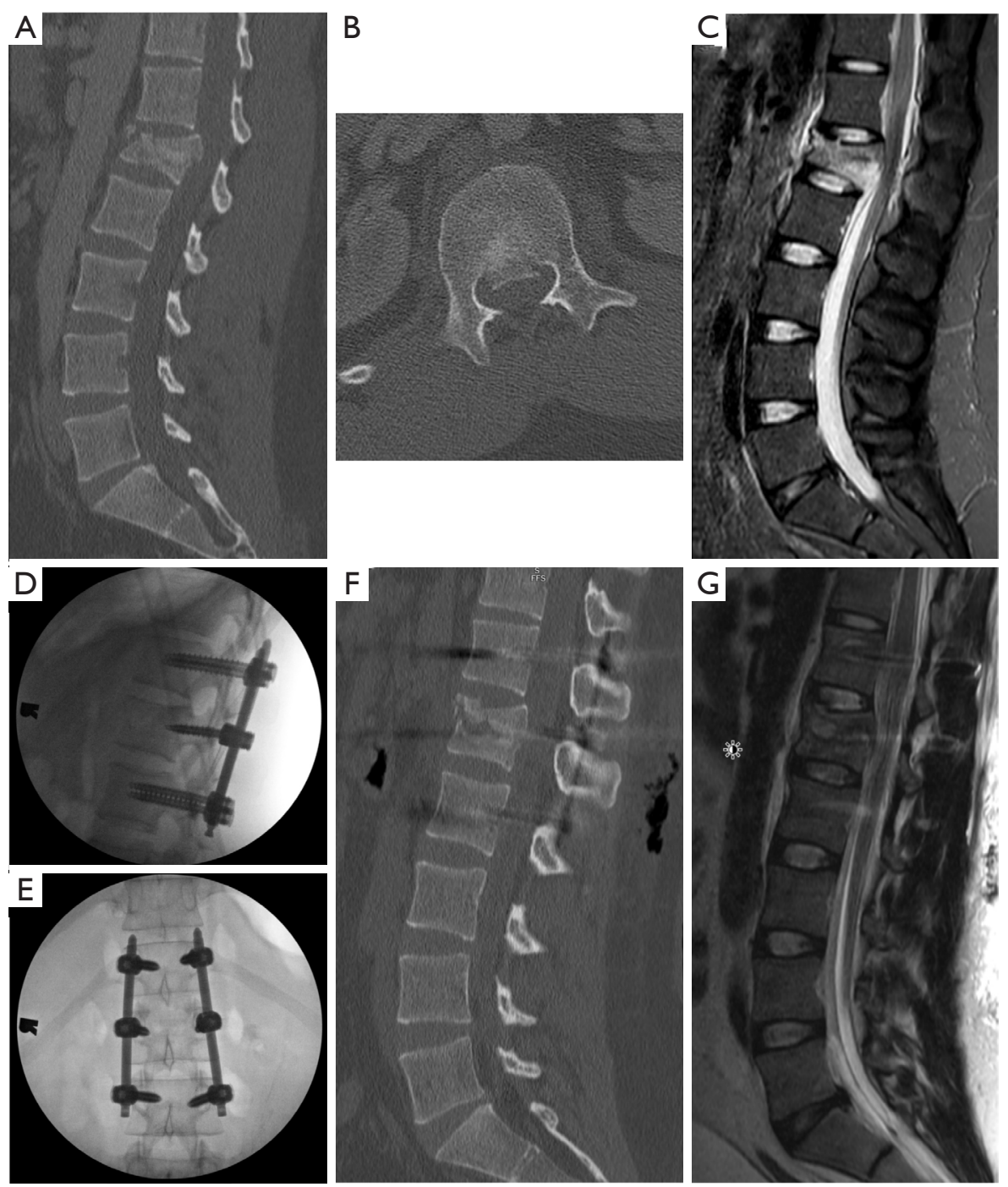

Figure 1 A young adult male who sustained an L1 burst fracture (A) in a motor vehicle accident. CT and MR imaging revealed some retropulsion $(B, C)$, but the patient lacked neurological deficits. Short-segment percutaneous pedicle screw fixation was performed with distraction across the segment was performed. Ligamentotaxis with ventral reduction of the retropulsed fracture and alignment restoration can be seen on intra-operative X-rays (D,E), and post-operative CT (F) and MR (G) imaging.

that osteotomies and/or decompression can be performed in tandem to achieve the appropriate level of correction (4). For mild angulating kyphosis related to the anterior wedging of the fracture, successful distraction can often be performed provided good bone quality and screw purchase. Figure 1 demonstrates an L1 burst fracture with short segment fixation in a young male after a motor vehicle accident. Index level screws were placed and distraction was performed (NuVasive ${ }^{\circledR}$ Reline $^{\mathrm{TM}}$ Trauma System, San Diego, CA) to restore height and correct the focal deformity. Despite having no neurological symptoms, retropulsion was seen on computed tomography and magnetic resonance imaging pre-operatively. Distraction across the fractured segment allowed for ligamentotaxis and anterior stretching of the retropulsed bone fragment, thereby decreasing canal encroachment. This technique is particularly affective in young patients with a severe fracture that may otherwise result in a kyphotic deformity after healing with an external brace alone. Furthermore, it allows for early mobilization, which may in turn help prevent other medical complications, such as atelectasis and venous thromboembolism. 


\section{Thoracolumbar flexion-distraction fractures}

Fewer reports have focused on percutaneous fixation for flexion-distraction injuries, however, it remains a consideration for this pathology as well (18). Though many of these fractures may not result in canal compromise, their severe instability merits consideration for surgical stabilization. Originally described by Chance, the fracture pattern can result in disruption of the posterior arch structure (19). This is reflected by their highest value on the TLICS scoring system of all the fracture morphologies (2). Unlike for burst fractures, the goal is typically compression across the fracture line, and this again comes largely from positioning. Distraction maneuvers during rod placement should be avoided to prevent worsening of the fracture displacement and/or neurological injury.

Percutaneous pedicle screw fixation can be performed with the aim to limit movement across the fracture line. Particularly with healthy young patients, internal bracing via this method allows for safe stabilization while the healing process occurs in patients that do not require open fracture reduction. Application of percutaneous fixation for flexiondistraction fractures has been demonstrated to be safe and resulted in less blood loss, trends toward shorter lengths of stay and operative duration, and resulted in no worse focal kyphosis at the time of surgery or follow-up compared to an open approach (18). Again, the authors prefer short segment fixation with a short screw through the pedicle at the index level when able. An example is seen in Figure 2 for a L1 chance fracture flexion-distraction type injury. Fixation one level above and one level below was performed. While bilateral index level screw placement is preferred, it can be seen that the fracture extends through one of the pedicles, preventing insertion on that side. Similar fixation applications to those flexion-distraction fractures seen in ankylosing spines of ankylosing spondylitis and diffuse idiopathic skeletal hyperostosis (DISH) have also been described $(20,21)$.

\section{Percutaneous vertebral augmentation}

In some cases, spinal fixation may not be warranted or may be contraindicated due to advanced age and/or severe osteoporosis. Since the 1980's, non-surgical treatments with vertebroplasty techniques consisting of percutaneous injection of polymethylmethacrylate (PMMA) cement have been in use (22). Outcome studies have shown that this technique may improve pain levels in certain patients, but have associated risks of cement leaking, which may in turn cause neurological deficits or pulmonary emboli (23-25). Advances have been made with the development of a balloonkyphoplasty, whereby percutaneous transpedicular balloon "tamps" (Kyphon, Inc., Sunnyvale, CA) are inflated within the vertebral body to create a cavity for cement injection. In theory this allows for low-pressure cement injection and therefore lower risk of cement embolization or extravasation into the spinal canal. Additionally, there are claims of improvement in kyphosis that can be seen due expansion of the compressed vertebral body, although the data supporting this remains equivocal (26). A recent series also demonstrated use of PMMA for vertebral body reconstruction after posterior corpectomy of pathological fractures with good results (27).

Other attempts have been made to design a specialized percutaneous bone graft delivery and containment system (Optimesh $^{\circledR}$, Spineology, Inc., St. Paul, MN) that stimulates ingrowth of new bone (21). Large studies demonstrating the outcomes for this technology still need to be performed to demonstrate efficacy in kyphosis correction or protection (28). However, some data suggests that non-operative treatment in young neurologically intact patients with mild traumatic compression fractures may result in worse disability outcomes at long-term follow-up despite following TLICS guidelines (29). It remains uncertain whether this is due to a loss of sagittal balance, but in following what's known from the degenerative adult spine deformity literature, this likely is a contributor in most instances. Therefore, consideration of an immediate kyphoplasty with percutaneous bone graft delivery and containment could be considered to help return the patient more reliably to their pre-traumatic condition. Further studies will be required to help confirm this suspicion.

Still, a growing interest remains regarding percutaneous augmentation combined with short-segment percutaneous pedicle screw fixation (30). In theory, injection of the index level with cement should reduce stress on the hardware and decrease the risk of post-surgical kyphosis. Most importantly, this could be employed in patients with questionable bone quality and higher risk of hardware failure. While maintenance of kyphosis has been demonstrated at long-term ( $>12$ months) follow-up with combined augmentation and short-segment fixation $(31,32)$, no studies directly comparing this method directly to fixation without cement have been performed. Given the reported risk of cement leakage seen in both of these studies, further evidence is required to substantiate the benefit of this cement supplementation to warrant its added risks. Careful patient selection may aid in defining those 

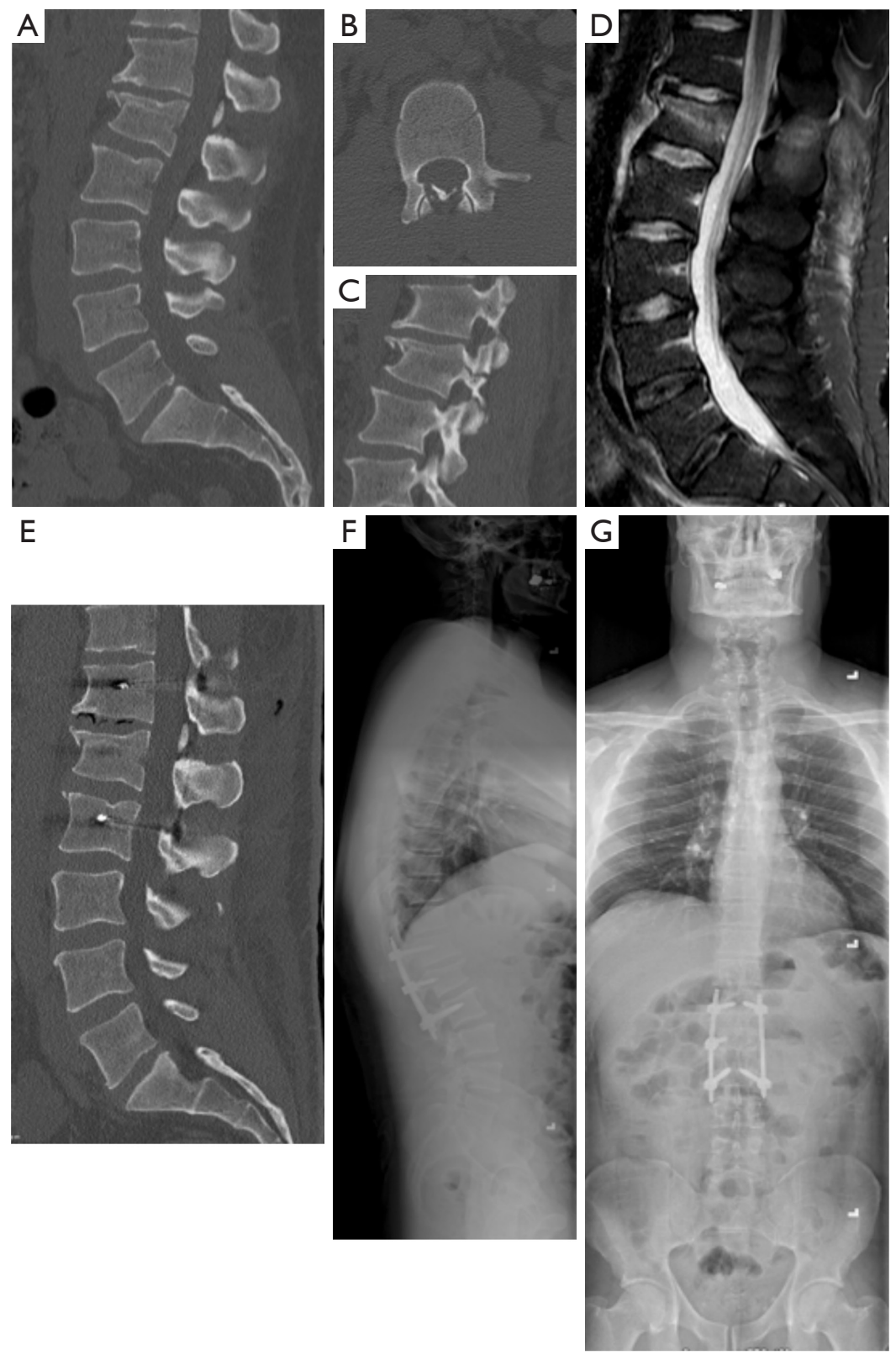

Figure 2 A young adult male who sustained an L1 flexion-distraction (Chance) fracture (A) in a motor vehicle accident. The fracture can be seen extending through the posterior elements (B,D) and the left pedicle (C) on CT and MR imaging. Short-segment percutaneous pedicle screw fixation was performed to internally brace the highly unstable fracture (E). Lateral (F) and anterior-posterior (G) standing scoliosis $\mathrm{X}$-rays demonstrate the stability of the construct with the patient upright.

cases where this benefit may be seen.

\section{Lateral approaches for thoracolumbar corpectomies}

Thoracolumbar fractures often result in retropulsion into the spinal canal, which may or may not cause neurological injury. Traditional posterior and posterolateral approaches are the standard of care for many surgeons as they allow for decompression of the posterior elements, provide a wide field for visualization the neural elements, and create exposure for pedicle screw fixation and posterolateral arthrodesis if 
required. Comparatively, anterior spinal approaches allow for direct visualization of the pathology and removal of the spinal compression, which in almost all instances exists ventral to the neural elements. Some studies have suggested that anterior approaches result in better neurological outcomes $(33,34)$. While many posterior approaches allow for access to the anterior column, anterior approaches obviate the need for thecal sac, spinal cord and nerve root retraction to gain access to the pathology (35). They additionally allow for easier replacement of the compromised bone with large expandable implant devices and restoration of the anterior column (36). This is preferred biomechanically, with good fusion rates, lower rates of subsidence and decreased risk of post-traumatic kyphosis.

As such, in the setting of thoracolumbar trauma, we will perform an anterolateral corpectomy if the patient has neurological symptoms warranting removal of offending retropulsed bone fragments. Similarly, we will consider placing anterior column support if we are concerned about sagittal alignment, as long-term kyphosis progression may result in delayed sagittal imbalance and spinal deformity, particularly in young patients with a long life-expectancy (37).

Originally devised for treatment of degenerative pathologies, mini-open lateral approaches have been adopted for applications requiring anterior column access, including trauma, and also infectious and neoplastic lesions as well (36). Compared to traditional transthoracic and retroperitoneal approaches, mini-open lateral approaches utilize retractors to gain focal access to the pathology under fluoroscopic guidance. This mitigates much of the morbidity related to pain and blood loss of open anterior approaches, and also removes the need for an access surgeon. Moreover, for thoracic pathologies, a retropleural access is used, thereby, omitting opening of the pleural cavity that is required with open transthoracic thoracotomies. Not only does this allow for standard duallumen ventilation during the procedure, but also decreases the chances of developing a duropleural cerebrospinal fluid fistula if the dura is violated (35).

\section{Surgical approach and considerations}

The surgical approach for lumbar fractures follows the tenets of those described for degenerative disease as described by Ozgur et al. $(38,39)$. For those at the thoracolumbar junction and thoracic spine, a retropleural approach is our preferred methodology $(39,40)$. Intra-operative fluoroscopy is vital to correct identification of the pathological level and to localizing the best location for incision and exposure. In thoracic cases, rib resection may be required for retractor placement. The fidelity of anteroposterior and lateral positioning of the patient and C-arm in orthogonal planes ensures accuracy during the approach and mitigates trajectory-related tension on the retractor throughout the case. Blunt finger dissection allows for safe ventral dissection of the peritoneum and/or parietal pleural between the transversalis and endothoracic fascia, respectively, while approaching the anterolateral spine. Palpation of the pathological level should guide dilator/retractor placement and $\mathrm{X}$-ray imagine can be used to verify positioning.

Once the retractor is in good position, an anterior retractor can be placed to protect visceral and vascular structures during the corpectomy. Segmental vessels crossing the pathology should be identified, coagulated and cut. Ventrally, a vertebrectomy is performed from disc space to disc space, and the dorsal retropulsed bone fragments are pushed away from the neural elements into this defect. In thoracic cases, the ipsilateral pedicle can also be removed so that the ventral edge of the dura can be visualized, and all work can be performed with maneuvers away from the spinal cord. In all cases, the posterior longitudinal ligament should be resected when able to safeguard against incomplete decompression.

Fluoroscopy can be performed to ensure that the corpectomy is complete in all directions. Once this is achieved, an expandable cage can be placed into the corpectomy site. We prefer to use a wide-footprint cage packed with locally collected morselized autograft and the surgeon's choice of allograft. Wide footprint rectangular cages (such as $\mathrm{X}$-CORE ${ }^{\circledR}, \mathrm{NuVasive}$, Inc.) span the hard cortical bone edges of the adjacent vertebral bodies and may help to decrease subsidence (41-43). This presents as one of the greatest advantages of the lateral approach compared to a posterolateral approach, where only a circular footplate cage can be placed. Fixation from the lateral approach can be performed to secure the construct by means of anterolateral plating. If bone integrity or biomechanical stability is unclear, percutaneous pedicle screw fixation can also be placed as a second stage. The necessity of this from a biomechanical standpoint remains uncertain, but can be considered for specific clinical situations. Figure 3 demonstrates an L1 burst fracture in a middle-aged female after a fall with evidence of a bone fragment retropulsion and conus medullaris compression. She demonstrated neurological deficits from the compression and therefore underwent a left-sided anterolateral corpectomy with placement of a wide footprint 

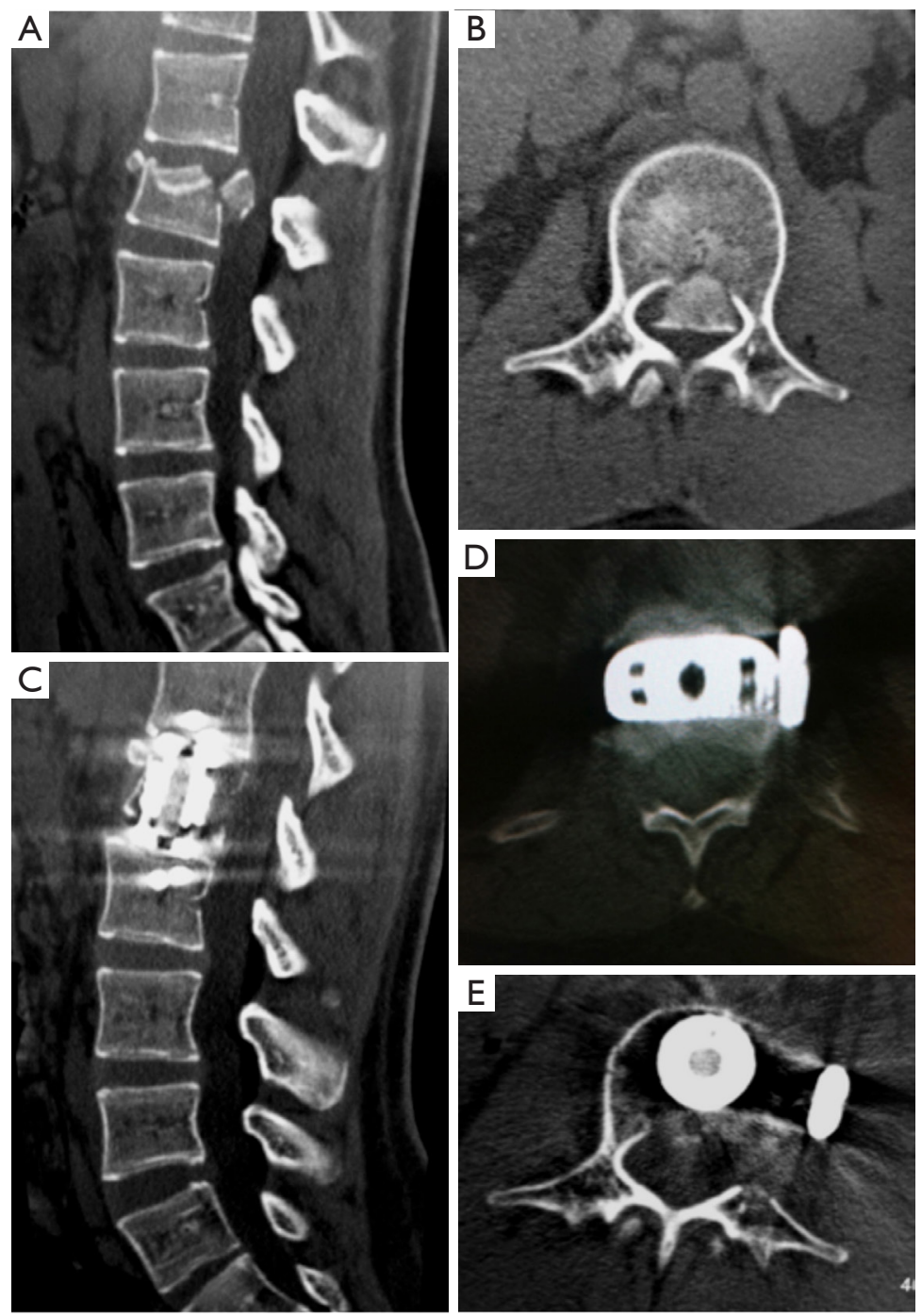

Figure 3 A middle-aged female who sustained an L1 burst fracture (A) after a high-elevation fall who presented with neurological symptoms consistent with conus medullaris compression as seen on CT imaging (B). She underwent emergent left mini-open anterolateral corpectomy with removal of the retropulsed bone fragment and placement of an expandable rectangular footplate vertebral body replacement device (C,D) and lateral plate fixation (E) with two screws each in T12 and L2.

expandable rectangular cage. Removal of the offending retropulsed bone fragment can be seen with maintenance of spinal alignment and lateral plate fixation.

\section{Clinical experience with minimally invasive corpectomies for trauma}

To date, our experience (WD Smith, JS Uribe) provides a large, modern experience with mini-open lateral approaches to thoracolumbar corpectomies for trauma (39).
In the published series of 52 patients treated with onelevel corpectomies between T7 and L4, treatment with a titanium cage and lateral plate fixation was performed, with several cases being backed up by supplemental pedicle screw fixation. Of note, in the first part of the study, circular footplate cylindrical titanium cages were used, and a transition to rectangular wide-footplate cages for the remainder of the study was made. Subsidence was noted in 7 of 34 of the cylindrical vertebral body replacement patients, and no cases of subsidence were seen in the 18 


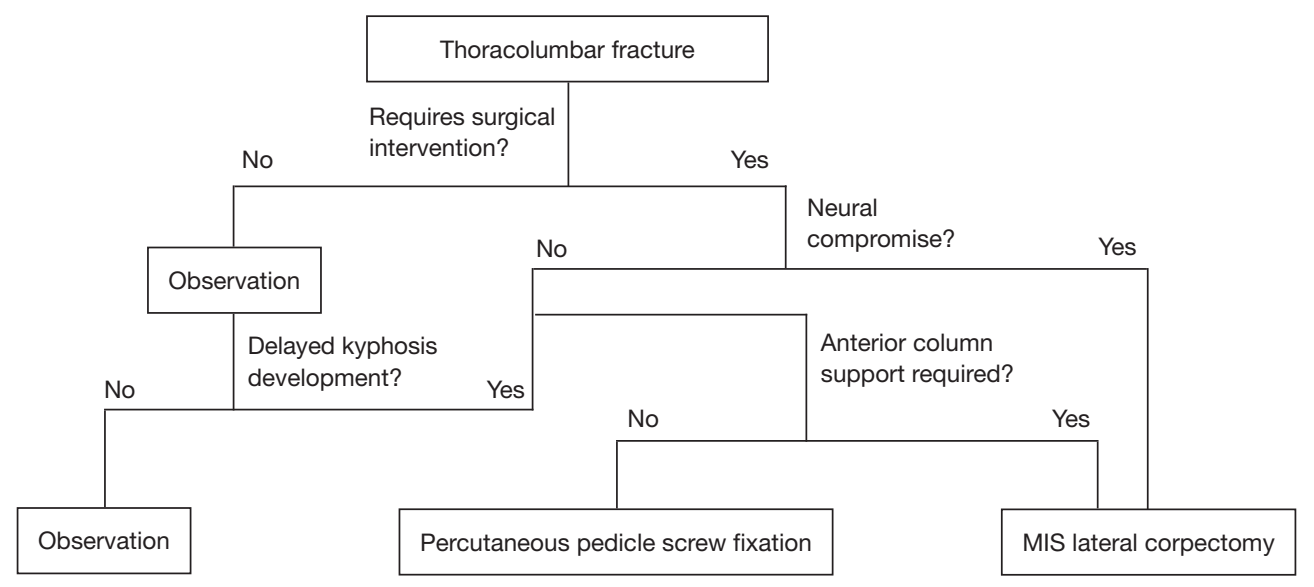

Figure 4 Schematic representation of the decision-making process for minimally invasive approaches to thoracolumbar trauma.

patients treated with rectangular plates. A complication rate of $15 \%$ was reported, and all patients in the study remained stable or improved neurologically with surgery in this series. Since the time of publication, we have continued to apply this treatment strategy with good results.

A number of other published experiences have examined mini-open lateral approaches for corpectomies of various etiologies. Baaj et al. (44) published a series of 80 patients who had corpectomies for trauma, infection and tumors. Their study demonstrated a similar overall complication rate of 12.5 percent. These complications included durotomies, intercostal neuralgia, deep venous thrombosis, pleural effusion, hemothorax, wound infection and hardware failure. Another study focusing on corpectomies for unstable lumbar burst fractures in 12 patients showed that when supplemented with short-segment posterior fixation this approach improved local lordosis, had good patient satisfaction outcomes and was tolerated well with minimal pain and morbidity (45). In their series, three of the patients required a chest tube for pleural violation and 1 patient required reoperation for cage subsidence/hardware failure. Similarly, we reported our experience with this approach for corpectomies for tumor in 13 patients between T8 and T12 with similar peri-operative results (operative duration, estimated blood loss, length of stay) and with only one infectious complication (pneumonia).

Limitations of a mini-open lateral approach also exist. Most obviously, it does not allow for visualization of the posterior elements or decompression of this column if it is necessary. Often, a posterior arch fracture co-exists with vertebral body lesions, and causes nerve compression or dural violation, and for these instances, an open posterior approach is preferable. Additionally, anatomical limitations allow for optimal access only between T6 and L4. Rostrally, the exposure is limited by the scapula, and caudally, by the iliac crest. Lumbar levels inherently contain risk to the lumbosacral plexus during psoas manipulation, especially at L4 where the nerves course ventrally.

Regarding the surgical approach itself, there is a moderate learning curve associated with minimally invasive techniques, including utilization of fluoroscopic guidance, retroperitoneal/retropleural retractor placement and the requirement of longer tools to operate down a long, narrow working space. As such, this procedure should be performed only by those spine surgeons with prior significant experience with both mini-open lateral approaches for degenerative disease and traditional open corpectomy techniques. This approach may be even more difficult to perform in morbidly obese patients due to an increased distance between the lateral incision point and the spine. It should also be noted that retropleural and retroperitoneal dissection can also become more difficult if adhesions exist in these spaces, which can often occur in the setting of multi-system trauma, or if applied to other inflammatory, infectious or neoplastic conditions.

\section{Conclusions}

Minimally invasive spine techniques provide stabilization, and when needed, decompression of the spine after thoracolumbar trauma (Figure 4). Percutaneous pedicle screw fixation allows for internal bracing during fracture healing with preservation of innervation, blood supply and muscular insertion. When appropriately applied, it can 
provide ligamentotaxis through distraction, biomechanical stabilization and spinal re-alignment. While definitive data still is lacking to support long-term fixation without posterolateral arthrodesis, this can likely be applied in most clinical situations safely without long-term risk of postsurgical kyphosis even after hardware removal. In the setting of neural compression and symptomatic fractures, miniopen lateral approaches allow for safe removal of the ventral retropulsed fracture with a corpectomy and vertebral body replacement to provide structural anterior column support. This allows for maximal neurological recovery and the best chance at maintaining normal spinal alignment for longterm functionality. Utilizing a minimally invasive lateral exposure yields sufficient visualization of the pathology to accomplish the aforementioned tasks, while minimizing pain, blood loss and morbidity compared to traditional anterior approaches.

\section{Acknowledgements}

None.

\section{Footnote}

Conflicts of Interest: Drs. JS Uribe, JD Turner and WD Smith are consultants for $\mathrm{NuVasive}^{\circledR}$, Inc. The other authors have no conflicts of interest to declare.

\section{References}

1. Lee JY, Vaccaro AR, Lim MR, et al. Thoracolumbar injury classification and severity score: a new paradigm for the treatment of thoracolumbar spine trauma. J Orthop Sci 2005;10:671-5.

2. Vaccaro AR, Lehman RA Jr, Hurlbert RJ, et al. A new classification of thoracolumbar injuries: the importance of injury morphology, the integrity of the posterior ligamentous complex, and neurologic status. Spine (Phila Pa 1976) 2005;30:2325-33.

3. Vanek P, Bradac O, Konopkova R, et al. Treatment of thoracolumbar trauma by short-segment percutaneous transpedicular screw instrumentation: prospective comparative study with a minimum 2-year follow-up. J Neurosurg Spine 2014;20:150-6.

4. Jiang XZ, Tian W, Liu B, et al. Comparison of a paraspinal approach with a percutaneous approach in the treatment of thoracolumbar burst fractures with posterior ligamentous complex injury: a prospective randomized controlled trial.
J Int Med Res 2012;40:1343-56.

5. Lee JK, Jang JW, Kim TW, et al. Percutaneous shortsegment pedicle screw placement without fusion in the treatment of thoracolumbar burst fractures: is it effective?: comparative study with open short-segment pedicle screw fixation with posterolateral fusion. Acta Neurochir (Wien) 2013;155:2305-12; discussion 2312.

6. Diniz JM, Botelho RV. Is fusion necessary for thoracolumbar burst fracture treated with spinal fixation? A systematic review and meta-analysis. J Neurosurg Spine 2017;27:584-92.

7. Wang ST, Ma HL, Liu CL, et al. Is fusion necessary for surgically treated burst fractures of the thoracolumbar and lumbar spine?: a prospective, randomized study. Spine (Phila Pa 1976) 2006;31:2646-52; discussion 2653.

8. Dai LY, Jiang LS, Jiang SD. Posterior short-segment fixation with or without fusion for thoracolumbar burst fractures. a five to seven-year prospective randomized study. J Bone Joint Surg Am 2009;91:1033-41.

9. Tezeren G, Bulut $\mathrm{O}$, Tukenmez M, et al. Long segment instrumentation of thoracolumbar burst fracture: fusion versus nonfusion. J Back Musculoskelet Rehabil 2009;22:107-12.

10. Jindal N, Sankhala SS, Bachhal V. The role of fusion in the management of burst fractures of the thoracolumbar spine treated by short segment pedicle screw fixation: a prospective randomised trial. J Bone Joint Surg Br 2012;94:1101-6.

11. Chou PH, Ma HL, Wang ST, et al. Fusion may not be a necessary procedure for surgically treated burst fractures of the thoracolumbar and lumbar spines: a follow-up of at least ten years. J Bone Joint Surg Am 2014;96:1724-31.

12. Yang H, Shi JH, Ebraheim M, et al. Outcome of thoracolumbar burst fractures treated with indirect reduction and fixation without fusion. Eur Spine J 2011;20:380-6.

13. Wang HW, Li CQ, Zhou Y, et al. Percutaneous pedicle screw fixation through the pedicle of fractured vertebra in the treatment of type A thoracolumbar fractures using Sextant system: an analysis of 38 cases. Chin J Traumatol 2010;13:137-45.

14. Wild MH, Glees M, Plieschnegger C, et al. Five-year follow-up examination after purely minimally invasive posterior stabilization of thoracolumbar fractures: a comparison of minimally invasive percutaneously and conventionally open treated patients. Arch Orthop Trauma Surg 2007;127:335-43.

15. McCormack T, Karaikovic E, Gaines RW. The load 
sharing classification of spine fractures. Spine (Phila $\mathrm{Pa}$ 1976) 1994;19:1741-4.

16. Koreckij T, Park DK, Fischgrund J. Minimally invasive spine surgery in the treatment of thoracolumbar and lumbar spine trauma. Neurosurg Focus 2014;37:E11.

17. Mobbs RJ, Raley DA. Complications with K-wire insertion for percutaneous pedicle screws. J Spinal Disord Tech 2014;27:390-4.

18. Grossbach AJ, Dahdaleh NS, Abel TJ, et al. Flexiondistraction injuries of the thoracolumbar spine: open fusion versus percutaneous pedicle screw fixation. Neurosurg Focus 2013;35:E2.

19. Chance GQ. Note on a type of flexion fracture of the spine. Br J Radiol 1948;21:452.

20. Nayak NR, Pisapia JM, Abdullah KG, et al. Minimally Invasive Surgery for Traumatic Fractures in Ankylosing Spinal Diseases. Global Spine J 2015;5:266-73.

21. Lam S, Khoo LT. A novel percutaneous system for bone graft delivery and containment for elevation and stabilization of vertebral compression fractures. Technical note. Neurosurg Focus 2005;18:e10.

22. Galibert P, Deramond H, Rosat P, et al. Preliminary note on the treatment of vertebral angioma by percutaneous acrylic vertebroplasty. Neurochirurgie 1987;33:166-8.

23. Heini PF, Walchli B, Berlemann U. Percutaneous transpedicular vertebroplasty with PMMA: operative technique and early results. A prospective study for the treatment of osteoporotic compression fractures. Eur Spine J 2000;9:445-50.

24. Tozzi P, Abdelmoumene Y, Corno AF, et al. Management of pulmonary embolism during acrylic vertebroplasty. Ann Thorac Surg 2002;74:1706-8.

25. Harrington KD. Major neurological complications following percutaneous vertebroplasty with polymethylmethacrylate : a case report. J Bone Joint Surg Am 2001;83-A:1070-3.

26. Burton AW, Rhines LD, Mendel E. Vertebroplasty and kyphoplasty: a comprehensive review. Neurosurg Focus 2005;18:e1.

27. Zuckerman SL, Rao G, Rhines LD, et al. Interbody distraction and vertebral body reconstruction with polymethylmethacrylate for the treatment of pathological fractures. J Neurosurg Spine 2017;27:700-8.

28. Schulz C, Kunz U, Mauer UM, et al. Percutaneous vertebral augmentation with polyethylene mesh and allograft bone for traumatic thoracolumbar fractures. Adv Orthop 2015;2015:412607.

29. Medici A, Meccariello L, Falzarano G. Non-operative vs. percutaneous stabilization in Magerl's A1 or A2 thoracolumbar spine fracture in adults: is it really advantageous for a good alignment of the spine? Preliminary data from a prospective study. Eur Spine J 2014;23 Suppl 6:677-83.

30. Verlaan JJ, Dhert WJ, Verbout AJ, et al. Balloon vertebroplasty in combination with pedicle screw instrumentation: a novel technique to treat thoracic and lumbar burst fractures. Spine (Phila Pa 1976) 2005;30:E73-9.

31. Fuentes S, Blondel B, Metellus P, et al. Percutaneous kyphoplasty and pedicle screw fixation for the management of thoraco-lumbar burst fractures. Eur Spine J 2010;19:1281-7.

32. Rahamimov N, Mulla H, Shani A, et al. Percutaneous augmented instrumentation of unstable thoracolumbar burst fractures. Eur Spine J 2012;21:850-4.

33. Kaneda K, Taneichi H, Abumi K, et al. Anterior decompression and stabilization with the Kaneda device for thoracolumbar burst fractures associated with neurological deficits. J Bone Joint Surg Am 1997;79:69-83.

34. McDonough PW, Davis R, Tribus C, et al. The management of acute thoracolumbar burst fractures with anterior corpectomy and Z-plate fixation. Spine (Phila $\mathrm{Pa}$ 1976) 2004;29:1901-8; discussion 1909.

35. McCormick PC. Retropleural approach to the thoracic and thoracolumbar spine. Neurosurgery 1995;37:908-14.

36. Scheufler KM. Technique and clinical results of minimally invasive reconstruction and stabilization of the thoracic and thoracolumbar spine with expandable cages and ventrolateral plate fixation. Neurosurgery 2007;61:798808; discussion 808-9.

37. Vaccaro AR, Silber JS. Post-traumatic spinal deformity. Spine (Phila Pa 1976) 2001;26:S111-8.

38. Ozgur BM, Aryan HE, Pimenta L, et al. Extreme Lateral Interbody Fusion (XLIF): a novel surgical technique for anterior lumbar interbody fusion. Spine J 2006;6:435-43.

39. Smith WD, Dakwar E, Le TV, et al. Minimally invasive surgery for traumatic spinal pathologies: a mini-open, lateral approach in the thoracic and lumbar spine. Spine (Phila Pa 1976) 2010;35:S338-46.

40. Uribe JS, Dakwar E, Cardona RF, et al. Minimally invasive lateral retropleural thoracolumbar approach: cadaveric feasibility study and report of 4 clinical cases. Neurosurgery 2011;68:32-9; discussion 39.

41. Pekmezci M, McDonald E, Kennedy A, et al. Can a novel rectangular footplate provide higher resistance to subsidence than circular footplates? An 
ex vivo biomechanical study. Spine (Phila $\mathrm{Pa} 1976$ ) 2012;37:E1177-81.

42. Reinhold M, Schmoelz W, Canto F, et al. A new distractable implant for vertebral body replacement: biomechanical testing of four implants for the thoracolumbar spine. Arch Orthop Trauma Surg 2009; 129:1375-82.

43. Mundis GM, Eastlack RK, Moazzaz P, et al. Contribution of Round vs. Rectangular Expandable Cage Endcaps to Spinal Stability in a Cadaveric Corpectomy Model. Int J

Cite this article as: Walker CT, Xu DS, Godzik J, Turner JD, Uribe JS, Smith WD. Minimally invasive surgery for thoracolumbar spinal trauma. Ann Transl Med 2018;6(6):102. doi: 10.21037/atm.2018.02.10
Spine Surg 2015;9:53.

44. Baaj AA, Dakwar E, Le TV, et al. Complications of the mini-open anterolateral approach to the thoracolumbar spine. J Clin Neurosci 2012;19:1265-7.

45. Theologis AA, Tabaraee E, Toogood P, et al. Anterior corpectomy via the mini-open, extreme lateral, transpsoas approach combined with short-segment posterior fixation for single-level traumatic lumbar burst fractures: analysis of health-related quality of life outcomes and patient satisfaction. J Neurosurg Spine 2016;24:60-8. 